\title{
OBITUARY
}

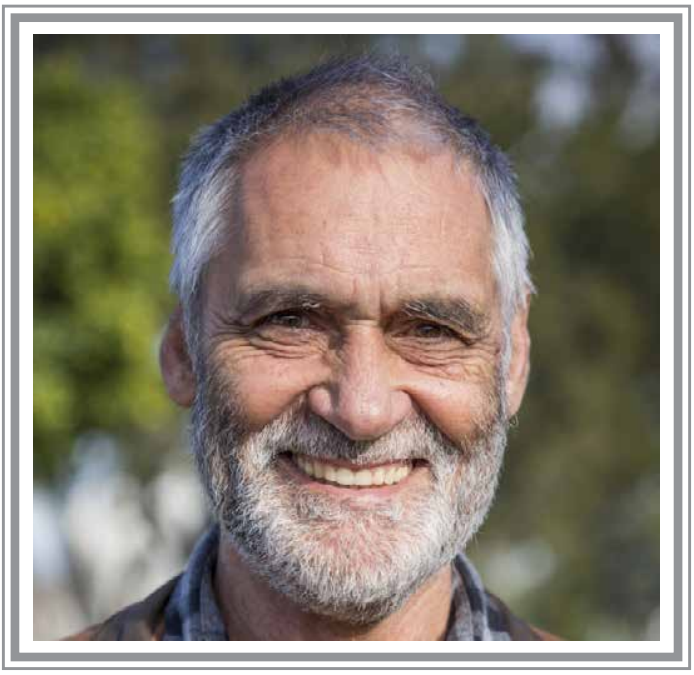

\section{Professor Wentzel C.A. Gelderblom (1951-2021)}

The international mycotoxicology community is mourning the passing of one of its stalwart members, Prof. Wentzel Gelderblom, affectionately known to us all as 'Blom'. After undergraduate studies, in 1980 he joined a research team of the South African Medical Research Council (SAMRC) investigating the then unknown carcinogen produced by Fusarium verticillioides. After his Masters and PhD studies on the mutagen fusarin C concluded that this was not the sought after carcinogen, Blom continued this research using a cancer initiation/promotion bioassay in rats, which resulted in his isolation and discovery of the carcinogenic fumonisins.

Blom went on to head the subprogramme Experimental Carcinogenesis at the PROMEC Unit of the SAMRC, before being promoted to be PROMEC director. With the unfortunate closure of PROMEC, he led his team into the Cape Peninsula University of Technology as Research Chair and the founding director of the Institute of Biomedical and Microbial Biotechnology.

Blom received the Visiting Scientist Award from the International Agency for Research on Cancer (IARC) working on the mechanisms of cancer induction of the fumonisins and served on international groups, such as the Joint FAO/WHO Expert Committee on Food Additives (JECFA) and IARC on the evaluation of risk parameters and carcinogenesis potency of the fumonisin B mycotoxins. He maintained many links with researchers both in USA and Europe and more recently contributed to two IARC publications on improving mycotoxin control, particularly in low- and middle-income countries.

Blom's research interests remained primarily focussed on fumonisins, their biochemistry, toxicology, mode of action, risk assessment, and risk management. Apart from fumonisins, Blom collaborated on ground-breaking research on the cancer preventative properties of dietary fatty acids and with researchers from the University of Stellenbosch on the putative health properties of two of South Africa's indigenous teas, rooibos and honeybush. He published widely in the scientific literature, where he was extensively cited, acted as supervisor for numerous $\mathrm{PhD}$ candidates and was frequently invited as session chair and speaker to international scientific conferences and workshops.

Apart from his science, Blom was a keen rose gardener and an inveterate runner, training in the early mornings, even during congresses, and he had frequently participated in two of South Africa's iconic ultramarathons. Perhaps better known to the mycotoxin community was his role as 'goalie' for the mycotoxin team at the traditional Gordon Research Conference soccer match. Some years ago Blom developed a passion for biking, bought a top-end motor bike and took to the open road with family as 'Blom-the-biker'.

Prof. Gelderblom had a passion for science, a deep commitment to his colleagues and students, and was a loving and caring family man. He will be widely missed by all of us who had the good fortune to know and work with him.

\section{Gordon S. Shephard}

Cape Peninsula University of Technology, Institute of Biomedical and Microbial Biotechnology, Cape Town, South Africa (retired); gshephard@mweb.co.za 
